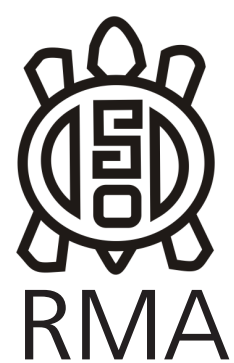

Arqueología

\section{Actividades domésticas durante los siglos III-VIII d.C. en el valle de Potrerillos (San Ignacio-Mendoza). Un acercamiento desde la osteometría y la tecnología cerámica y lítica}

\author{
Alejandra Gasco*, Erik J. Marsh**, Cecilia Frigolé***, Silvina \\ Castro***, Claudia Privitera***, Rosa Moyano* y Lucía Yebra***
}

\begin{abstract}
*CONICET, Laboratorio de Geo-Arqueología, Universidad Nacional de Cuyo. E-mail: soljandra@yahoo.com.ar ; rosamoyano77@yahoo.com.ar, **Departamento de Antropología, Universidad de California, Santa Bárbara E-mail: emarsh@umail.ucsb.edu , *** Laboratorio de Geo-Arqueología, Universidad Nacional de Cuyo, E-mail: fr_ceci@ hotmail.com; marielprivitera@gmail.com; yebralucia@hotmail.com, ****ANPCyT, Laboratorio de Geo-Arqueología, Universidad Nacional de Cuyo, E-mail: silcastro24@hotmail.com
\end{abstract}

\begin{abstract}
Resumen
San Ignacio, en el Valle de Potrerillos, fue habitado durante los siglos III-VIII D.C. por grupos humanos que construyeron hornillos y ocuparon casas semi-subterráneas. Constituye uno de los escasos registros sistemáticos de contextos domésticos para el valle. Se presenta y caracteriza el sitio mediante el análisis osteométrico de camélidos, la organización de la tecnología lítica y el análisis tipológico y morfo-funcional cerámico. Las diversas actividades domésticas desarrolladas combinaron la explotación de camélidos silvestres y domésticos, además de cultígenos. Los rasgos arquitectónicos y los patrones materiales del interior de la unidad habitacional, se relacionan con una ocupación anticipada de tipo permanente. La cerámica analizada fue asignada al estilo Agrelo-Calingasta del período Agro-alfarero Temprano-Medio de la arqueología regional. El asentamiento podría insertarse en un circuito de movilidad para el aprovechamiento de diversos recursos en ambientes de altura. Además se sugiere la participación en redes de intercambio, evidenciada por la presencia de cerámica similar a la de los complejos culturales que se desarrollaron en la vertiente occidental de Los Andes y por la identificación de un morfotipo de camélido especialmente grande, propicio para la realización de caravanas.
\end{abstract}

Palabras clave: Valle de Potrerillos; Período Agro-alfarero regional; Contexto Doméstico; Camélidos silvestres y domésticos; Redes de Intercambio.

Domestic activities during the III-VIII centuries AD in Potrerillos Valley (San Ignacio, Mendoza). An osteometric, ceramic and lithic technology approach.

\begin{abstract}
San Ignacio, in the Valley of Portrerillos was occupied during the third to eighth centuries A.D. by groups that constructed pit ovens and occupied semi-subterranean houses. It is one of the few systematically recorded domestic contexts in the valley. The site is presented and characterized through the osteometric analysis of camelids, the organization of lithic technology, and typological and morphofunctional analyses of ceramics. Diverse domestic activities combined the exploitation of wild and domestic camelids, as well as cultigens. Architectural features and material patterns from the interior of the habitation imply a permanent occupation. The analyzed ceramics were associated with the style Agrelo-Calingasta from the regional Early-Middle Agro-ceramic period. The settlement may be part of a mobility circuit for the utilization of diverse resources in high altitude zones. Moreover, participation in exchange networks is suggested by the presence of ceramics similar to those used by cultural complexes on the western slopes of the Andes and the identification of an especially large camelid morphotype, apt for carrying out caravans.
\end{abstract}

Keywords: Valley of Portrerillos; Regional Agro-ceramic Period; Domestic Context; Wild and Domestic Camelids; Exchange Networks.

Recibido 09-02-2011. Recibido con correcciones 03-06-2011. Aceptado 12-10-2011 
El sitio arqueológico San Ignacio, localizado en el valle intermontano de Potrerillos, fue ocupado entre ca. 240 y 780 cal D.C. por grupos humanos que construyeron hornillos y casas de estructura semicircular y semisubterránea. Este trabajo presenta una descripción y caracterización del sitio inédito hasta el momento; además pretende contribuir con la historia cultural de la región durante el Holoceno tardío.

La cuenca del río Blanco forma parte de un área de investigación con más de 10 años de trabajos arqueológicos sistemáticos (Cortegoso 2004). Esta amplia región muestra una importante diversidad de ambientes (desde Cordillera Frontal hasta valles intermontanos), entre los cuales el Valle de Potrerillos presenta las cotas más bajas y los primeros registros de sitios a cielo abierto (canteras, talleres líticos y estructuras habitacionales) para el Holoceno tardío (Durán et al. 2002, Cortegoso $2006,2008)$. San Ignacio constituye el registro de una de las tres estructuras habitacionales estudiadas en el valle de forma sistemática para la arqueología local y cobra relevancia dada su temprana cronología y la asociación por proximidad a cuatro hornillos (Gasco et al. 2010).

El presente estudio tiene como objetivo establecer las actividades domésticas llevadas a cabo en el sitio, mediante el estudio de ciertos restos materiales hallados en el interior de una unidad habitacional. Para ello se presenta una descripción geomorfológica y ambiental del área en donde se emplaza el sitio en estudio; luego se presentan los rasgos arquitectónicos y otras características de la casa-pozo junto a los posibles momentos de ocupación. Se trabaja sobre el registro arqueofaunístico correspondiente a camélidos, para discriminar entre las especies de dichos ungulados, intentando establecer la presencia de individuos domésticos. Además, estos resultados son vinculados con los obtenidos mediante el estudio de la organización de la tecnología lítica y los análisis morfo-funcionales de cerámica.

\section{Geomorfología, Ambiente y Recursos}

Potrerillos es un valle longitudinal con dirección N-S entre la Cordillera Frontal y la Precordillera, atravesado por el Río Mendoza (Valpreda et al. 2002). Las cotas bajas, ubicadas a 1.400 msnm, al drenar en el valle del Río Mendoza, desarrollan terrazas abiertas, con agua permanente y clima templado. Estos sectores son los que presentan una mayor explotación moderna y, por lo tanto, han sufrido una fuerte transformación e impacto ambiental, con una densa ocupación de espacio en el fondo del valle.

La presencia del Río Mendoza asegura la disponibilidad de agua aún en períodos secos. Este es uno de los cauces más grandes y de curso perenne que franquea a la vez el sinclinal de Potrerillos y la Precordillera (González Días y Fauqué 1993). Además de contar con condiciones más benignas que las de Cordillera y Precordillera, el valle ofrece un lugar muy reparado donde excepcionalmente se acumula nieve en invierno (Cortegoso 2008).

En términos generales el ambiente presenta vegetación rala con pisos de arbustos bajos y coironales hasta los $3.000 \mathrm{msnm}$. En el área estudiada se dan las situaciones de mayor variabilidad y superposición fitogeográficas. La zona de mayor altura comprendida en la provincia andina (bioma andino), una cuña longitudinal de la provincia puneña (bioma puneño) y la provincia del cardonal (bioma chaqueño) sobre todo en el sector más cercano a la Precordillera. En el sector del valle se incluye el tipo de Vegetación de Bolsones y Huayquerías, específicamente el subtipo caracterizado por bajadas arbustivas de Larrea divaricata y Larrea cuneifolia y la presencia de chañares (Geoffroea decorticans) asegura la disponibilidad de leña (Roig et al. 2000).

La fauna silvestre es más visible en las estribaciones precordilleranas de la margen izquierda del Río Mendoza, dado que es uno de los espacios con menor impacto antrópico, por lo menos a nivel de instalación permanente. Hay una gran cantidad de roedores, sobre todo cuises (Galea musteloides y Microcavia sp) y tunduques (Ctenomys mendocinus), mamíferos de mayor tamaño como zorros grises (Pseudalopex griseus), pumas (Felis concolor) y guanacos (Lama guanicoe). También se avista una gran variedad de aves silvestres como cóndores (Vultur gryphus) y águilas (Geranoaetus melanoleucus).

En cuanto a recursos abióticos, el valle cuenta con disponibilidad de fuentes de arcilla de muy buena calidad (Moyano et al. 2010). Además, con respecto a las rocas, existe una importante diversidad en cuanto a calidades para la talla, localizándose, sobre la margen derecha del río Mendoza, fuentes de riolita, basalto, arenisca y granito (Cantera Paleomédanos). En la margen izquierda, sobre el piedemonte occidental de la Precordillera, se localizan fuentes de rocas silíceas y calcita (Cantera Los Conitos) (Cortegoso 2008). Ambas fuentes se encuentran ubicadas aproximadamente a $1 \mathrm{~km}$ del sitio San Ignacio. En Cordillera se han registrado fuentes de riolitas, cuarzo lechoso, cuarcitas y granito, y en áreas más alejadas se han localizado silíceas de excelente calidad para la talla (e.g. Paramillos a $50 \mathrm{~km}$ ).

\section{Sitio San Ignacio: casa-pozo y hornillos}

El sitio arqueológico San Ignacio se encuentra emplazado en el valle antes descripto, a unos $45 \mathrm{~km}$ de la Ciudad de Mendoza, sobre la margen izquierda, en la segunda terraza del Río Mendoza (Figura 1). Es una formación de limos-arcillosos de casi $2 \mathrm{~m}$ de espesor con material arqueológico estratificado.

Esta zona fue ocupada por la Estancia San Ignacio desde las primeras décadas del siglo pasado hasta aproximadamente 1960. La actividad agrícola que se 


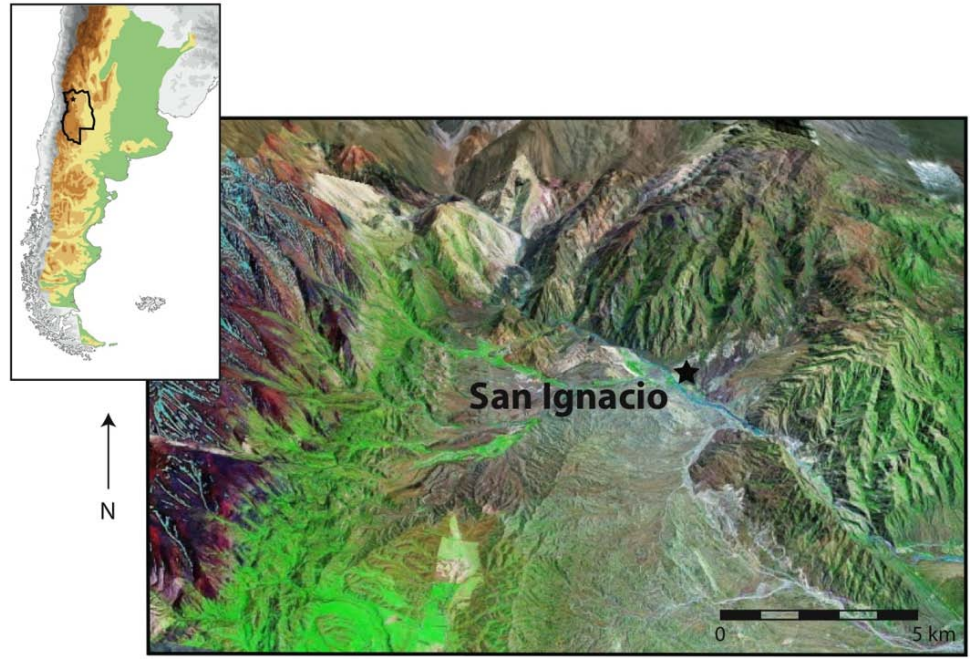

Figura 1. Mapa de localización del sitio San Ignacio. Perspectiva 3D del Valle de Potrerillos, vista al Norte. Basado en una imagen LANDSAT-7 del 2000, antes de la construcción del Dique. Datos de altura de Google Earth realzados.

Figure 1. Map showing the location of the site San Ignacio. 3D perspective of the Potrerillos Valley, facing north. Based on LANDSAT-7 imagery from the year 2000, before the construction of the dam. Elevation data from Google Earth, exaggerated for effect.

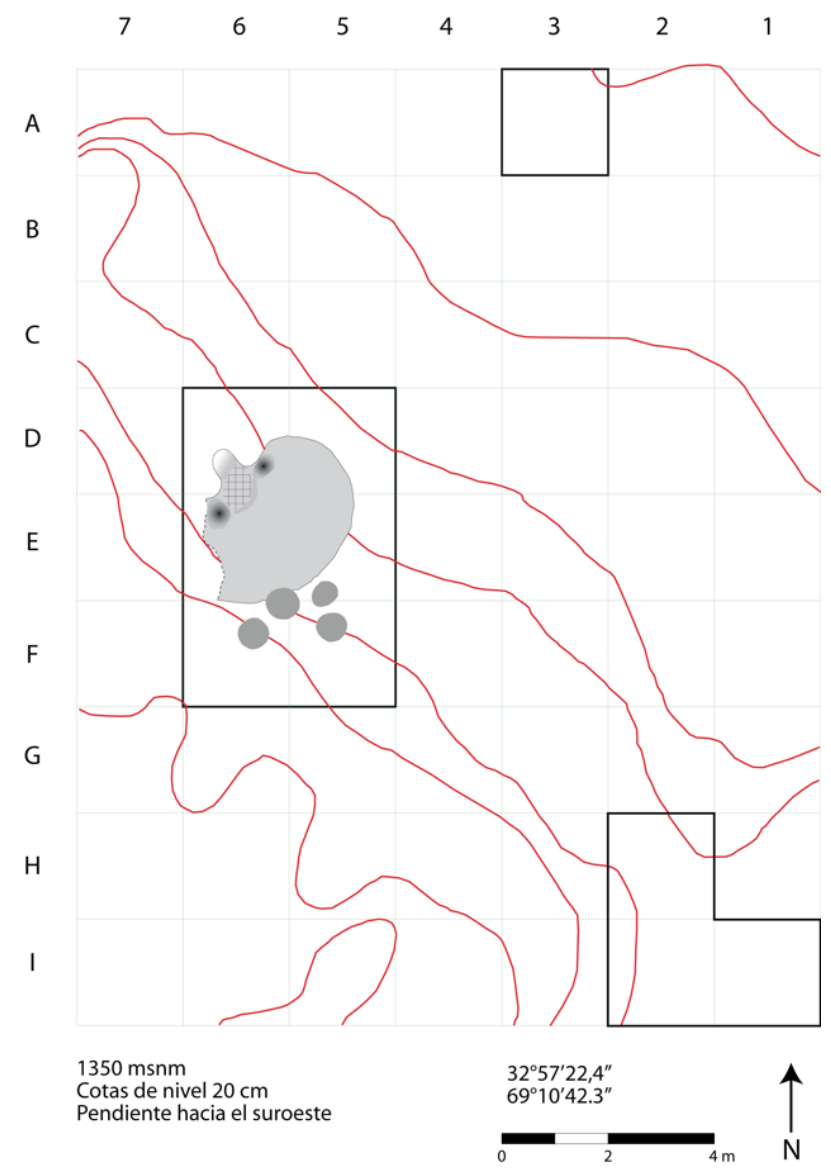

Figura 2. Planimetría de San Ignacio. Reticulado de prospección.

Figure 2. Plan of San Ignacio. Survey grid. realizó dañó las ocupaciones prehistóricas que parcialmente se encuentran bordeando las barrancas en más de $1 \mathrm{~km}$ de longitud por unos $100 \mathrm{~m}$ de ancho. Asimismo la construcción de la traza del ferrocarril Trasandino, perjudicó la capa superior de la última ocupación arqueológica (Durán et al. 2002). Finalmente, toda la zona fue afectada por la construcción del Dique de Potrerillos y particularmente la acción de máquinas alteró aproximadamente $1 \mathrm{~m}$ de profundidad de sedimento quedando al descubierto abundante material lítico, cerámico y óseo en superficie.

Las actividades de rescate arqueológicas se realizaron en dos etapas: julio y agosto de los años 2001-2002 respectivamente. Las prospecciones se efectuaron mediante un reticulado de $18 \times 12 \mathrm{~m}$ en donde se practicaron varios sondeos exploratorios. Se descubrieron cuatro estructuras de combustión (hornillos) y una unidad doméstica (casapozo) (Figura 2). Esta última fue intervenida mediante una excavación sistemática, siguiendo niveles artificiales de 5 y $10 \mathrm{~cm}$ hasta alcanzar suelos estériles.

La unidad de habitación es semisubterránea de planta semicircular de aproximadamente 3,60 m de diámetro por 0,60 $\mathrm{m}$ de profundidad (Figura 3 y Figura 4). Las diferencias de sedimentos en el interior de la casa-pozo podrían dar cuenta del colapso de la vivienda, así como de diferentes momentos de ocupación del espacio (ver más adelante).

La matriz sedimentaria en los primeros niveles ( 1 a 6 ; hasta $0,35 \mathrm{~m}$ de profundidad aproximadamente) se presenta integrada por "terrones" de sedimento limo-arcilloso, rojizo, algunos incluyen pequeños clastos "aladrillados" e improntas de vegetales, y en la mayoría de los casos, sus intersticios muestran arena fina grisácea de color gris a gris verdosa. Esto podría evidenciar el colapso de la vivienda, con lo cual ese sedimento, con improntas vegetales y arenas, correspondería a la parte aérea de la casa (Figura 3). Además, desde el Hornillo №2 hacia el NO, es en dónde aparece la mayor concentración de este tipo de sedimento junto a material antrópico variado, sobre todo instrumentos de molienda, rodados y núcleos. Estas características sedimentarias son muy similares a las del interior del Hornillo $\mathrm{N}^{\circ} 2$, por lo cual este patrón material pudo ser generado a través del uso y limpieza de dicho hornillo. La presencia de la pared de la casa en el interior del hornillo podría evidenciar que la construcción de mismo y las actividades de su uso y limpieza fueron posteriores a la casa-pozo.

En los niveles posteriores ( 7 a $11 ; 0,40$ a $0,60 \mathrm{~m}$ de profundidad) el sedimento es de matriz limo-arcillosa, estructura semicompacta, de color gris, con cenizas y abundantes espículas de carbón de tamaño y 


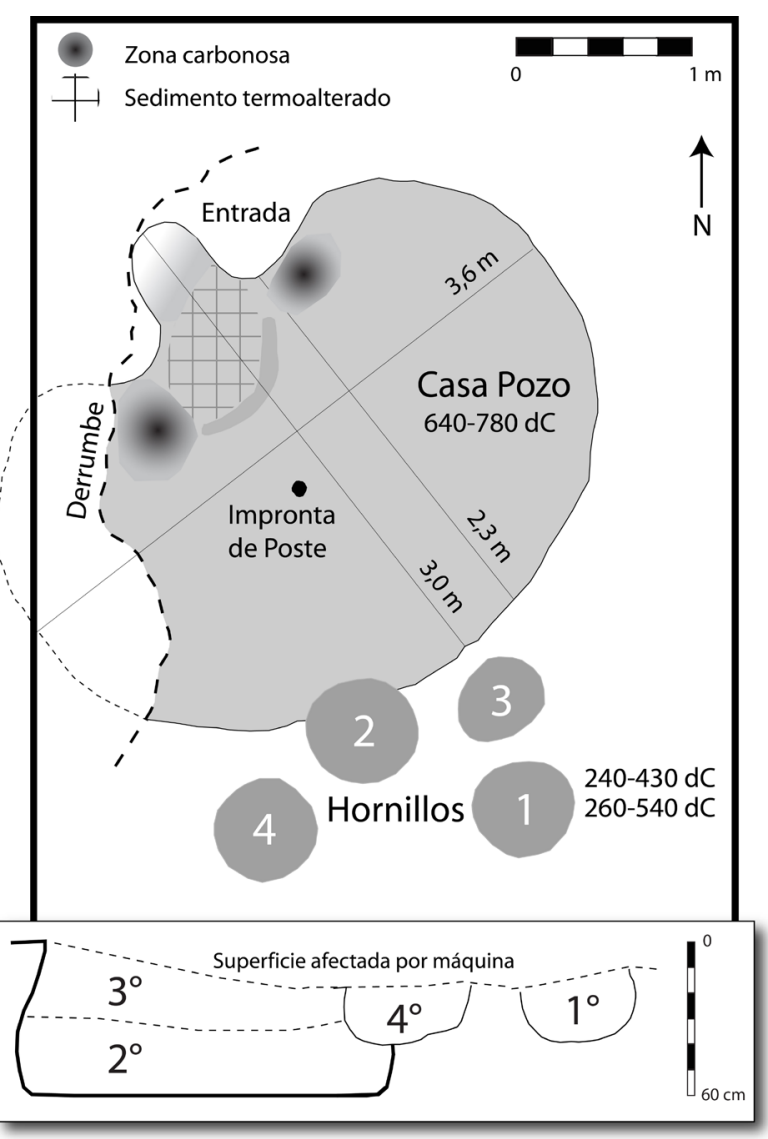

Figura 3. Planta de la estructura habitacional y de los hornillos hallados en San Ignacio y perfil idealizado mostrando los cuatro momentos ocupacionales del sitio.

Figure 3. Map of the habitational structure and the earthern ovens found in San Ignacio, and the idealized profile, showing the four moments of occupation of the site.

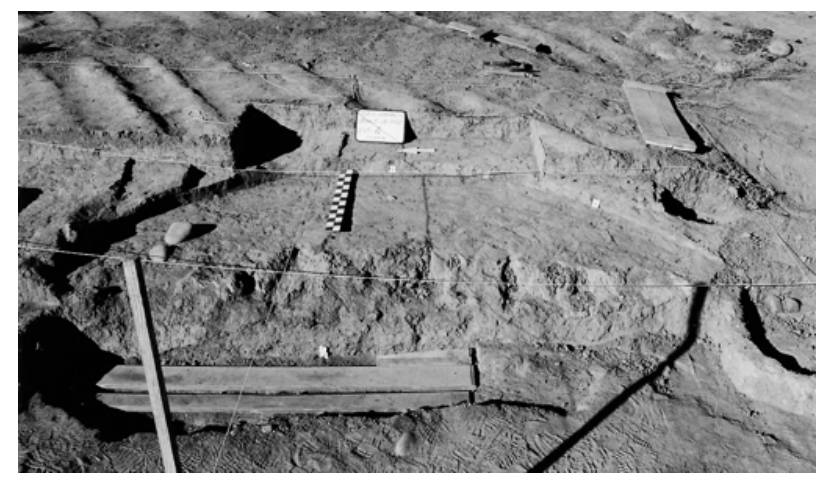

Figura 4. Casa-pozo y Hornillo $N^{\circ} 2$. Fuente: Laboratorio de GeoArqueología, F.F.y L., U.N.Cuyo.

Figure 4. Pit-house and earthen oven no. 2. Source: Laboratory of Geoarchaeology, F.F.y L., U.N.Cuyo.

concentración variable, también con diferente material antrópico. El piso de la estructura doméstica aparece a 0,60 $\mathrm{m}$ de profundidad aproximadamente, es una superficie compactada (tal vez por pisoteo) que se desprende fácilmente del sedimento suprayacente. La matriz del piso es arena fina de color gris a gris verdosa, además es carbonosa y en ella aparecen restos de origen antrópico, resulta llamativo su grado de nivelación. La arena descripta aparece también en lo que serían las "paredes" de la casa-pozo y es de aproximadamente 2-3 $\mathrm{mm}$ de espesor, y separa claramente el interior del exterior de la unidad habitacional.

Los rasgos arquitectónicos destacados son la "entrada" y el "fogón" principal. La entrada se localiza en el sector NO de la estructura. Es un sedimento compacto que presenta una leve inclinación (rampa) sin material antrópico. El fogón aparece inmediatamente de concluido el plano inclinado que constituye la entrada a la casa, sobre una leve depresión con un reborde de arcilla termo-alterada (en forma de "anillo") que parece contenerlo. En él se halló evidencia de perturbación por fosoriales y el sedimento es termoalterado con abundantes espículas de carbón. A ambos lados de la zona termoalterada, el sedimento cambia a carbonoso, con altas cantidades de carbón y cenizas. También casi en el centro de unidad aparece una impronta de poste (Figura 3).

En cuanto a los materiales antrópicos hallados en el interior de la unidad doméstica se pueden mencionar: elementos de adorno corporal (tembetás), cuenta de nacar, huesos pulidos, fragmentos de carbón, molinos con pigmentos rojos y ocres adheridos, manos de moler, rodados, núcleos, lascas, fragmentos de cerámica, diferentes restos óseos, guijarros, improntas de junco, semilla de poroto y marlo de maíz calcinado ${ }^{11}$.

Fuera de la unidad habitacional antes descripta se hallaron cuatro hornillos (Figuras 3 y 5). Estas estructuras posiblemente fueron empleadas no sólo para la cocción de alimentos, sino también para la de la cerámica hallada en el sitio. En general el tamaño de los hornillos ronda los $50 \mathrm{~cm}$ de diámetro por $30 \mathrm{~cm}$ de profundidad. En su interior, en general, la matriz sedimentaria es arenosa suelta con abundantes restos de carbón, cenizas, rocas termoalteradas y variado material antrópico (lítico, restos óseos y botánicos).

Recientemente se dispone de tres fechados radiocarbónicos, uno para la casa-pozo de $1310 \pm 40$ años AP (URU-0301) sobre el piso, y dos para el Hornillo $N^{\circ} 1$ de $1630 \pm 40$ años AP (URU-0302) y 1690 \pm 40 años AP (URU0305), en la parte superior e inferior respectivamente. Hasta el momento, y considerando los fechados, estratigrafía y disposición de las estructuras se proponen cuatro posibles momentos de ocupación (Figura 3):

$$
\begin{aligned}
& 1^{\circ} \text { - Hornillo } N^{\circ} 1: 430 \text { cal D.C. (260-540, } 2 \text { sigma) } \\
& 350 \text { cal D.C. (240-430, } 2 \text { sigma) } \\
& 2^{\circ} \text { - Casa-pozo: } 710 \text { cal D.C. (640-780, } 2 \text { sigma) } \\
& 3^{\circ} \text { - colapso de la casa-pozo y/o desuso de la misma } \\
& 4^{\circ} \text { - construcción y uso del Hornillo } N^{\circ} 2
\end{aligned}
$$

\footnotetext{
${ }^{1}$ Los restos botánicos no han sido abordados en detalle en este trabajo por estar en proceso de análisis. No obstante, su presencia conlleva implicancias de gran importancia para este estudio.
} 


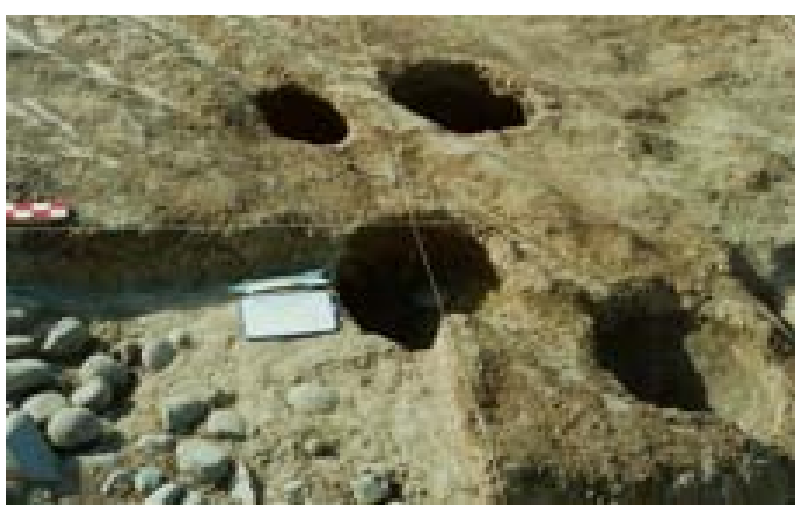

Figura 5. Hornillos. Fuente: Laboratorio de Geo-Arqueología, F.F.y L., U.N.Cuyo.

Figure 5. Earthen Ovens. Source: Laboratory of Geoarchaeology, F.F.y L., U.N.Cuyo.

Entonces, según las calibraciones de los fechados radiocarbónicos puede decirse que el sitio San Ignacio estuvo ocupado durante un lapso que abarca al menos los siglos III a VIII D.C.; sin embargo, no puede sostenerse que dicha ocupación haya sido continua. El sitio se adscribe a ocupaciones agro-alfareras correspondientes a la fase cultural Agrelo-Calingasta del período Temprano-Medio de la arqueología regional (Durán et al. 2002:71).

Los patrones arquitectónicos y las características de los restos materiales, evidencian una ocupación permanente del espacio. Siguiendo las expectativas materiales manejadas por Kent (1992), los pobladores de esta unidad habitacional anticiparon un uso prolongado del sector y no de tipo estacional y/o específico, como el evidenciado en otros sitios de ambientes de altura tanto en Cordillera como Precordillera (Cortegoso 2004, Frigolé 2010). Como en otros sitios similares de ocupación prolongada, San Ignacio presenta rasgos arquitectónicos (tanto de la casa-pozo como de los hornillos) que demandan una alta inversión de tiempo en lo referido a actividades de construcción, mantenimiento y uso (McGuire y Schiffer 1983:283). Es probable que San Ignacio formara parte de un circuito de movilidad mayor que incorporaba la ocupación de otros sitios en diferentes ambientes, de tipo estacional y/o temporal vinculados a la explotación de diversos recursos (líticos, pasturas, guanacos).

La descripción de esta casa-pozo y del material hallado en su interior, resultan notablemente similares a las estructuras habitacionales halladas en la provincia de San Juan en Punta del Agua-Los Morrillos (Gambier 1977:3537, Figuras 22-28) e inclusive presentan los mismos fechados; y también a las casas subterráneas $\mathrm{N}^{\circ} 1$ y N² del Basurero Norte de Punta del Barro, sobre todo en los rasgos arquitectónicos que muestran las estructuras, por ejemplo el fogón y entrada (Gambier 1988:37, Figura 50-51). Los grupos que construyeron e hicieron uso de dichas estructuras habitacionales fueron caracterizados como miembros de una sociedad agro-ganadera en base de la existencia de restos de vegetales cultivados, canales, campos de cultivo artificialmente preparados, excremento de animales conteniendo vegetales cultivados, corrales, textiles con lana de vicuña, guanaco y llama, entre otras evidencias materiales (Gambier 2000 y citas en él). Por la comparación realizada se podría suponer una afiliación cultural entre los pobladores de los dichos sitios en San Juan y los del Valle de Potrerillos para el lapso temporal abordado.

\section{Registro Material: falanges de camélidos, cerámica y lítico}

\section{Osteometría en falanges de camélidos}

Se trabajó sobre aquellos elementos óseos arqueológicos asignados taxonómicamente a Camelidae y anatómicamente a primeras, segundas y terceras falanges (delanteras y traseras) (Tabla 1). Los especímenes medidos muestran madurez ósea y no presentan evidencias de termoalteración, meteorización ( $\leq 3$ sensu Behresmeyer 1978) o patologías. Las primeras falanges fueron discriminadas entre anteriores (delanteras) y posteriores (traseras) a partir de rasgos morfológicos (Cartajena 2002, 2009; Kent 1982) y comparaciones estadísticas con la colección de referencia; este paso fue necesario dada la superposición en los rangos de las medidas de estos elementos entre las distintas especies de camélidos.

Se siguió un criterio cuantitativo, a partir de la osteometría y la aplicación de análisis bi y multivariados sobre sus resultados. Este análisis es dado por discriminación de los especímenes asignados a Camelidae, mediante el análisis morfológico-comparativo de elementos postcraneales (Izeta 2007). Se seleccionó la osteometría para el acercamiento a la identificación de los especímenes por ser una técnica bastante sencilla y difundida y porque sus resultados pueden ser replicables (Belloti 2007; Grant 2008; Izeta 2009). Para el empleo de esta técnica, el material actual comparativo empleado se obtuvo de diferentes instituciones científicas y educativas, y de particulares de Bolivia, como así también de Mendoza y San Juan, y los datos métricos y algunos ejemplares están disponibles en el Laboratorio de Geo-Arqueología (F.F.yL.-U.N.Cuyo), (Gasco y Marsh 2011:Tabla 2), -más detalles ver Resultados y Discusiones. Además, de Kent (1982) se consideró el dato promediado de cada variable métrica para cada elemento por especie de camélido. Se utilizó como guía de mediciones la establecida por Kent (1982:Apéndice IV; Izeta et al. 2009, Privitera 2011). Las variables continuas se obtuvieron mediante un calibre digital (precisión $0.01 \mathrm{~mm}$ ). Los análisis estadísticos se efectuaron mediante el uso del software PAST (Hammer et al. 2001). Se aplicó un análisis de agrupamiento UPGMA (Unweighted Pair Group Using Arithmetical Averages), utilizando el coeficiente de similitud euclideano, resultando un fenograma para cada elemento o conjunto de elemento (Cardich e Izeta 1999; Menegaz et al.1989). En paralelo se realizó un análisis de 
componentes principales (en adelante ACP) a partir de matrices de correlaciones.

Primera falange. Considerando las variables disponibles (V2/V3) en las primeras falanges posteriores (NSP=3, Tabla 1.a), el análisis de similitud permite separar cuatro subgrupos. Uno de ellos vinculado a Lama glama y al promedio de los ejemplares correspondientes a Vicugna pacos tomado de Kent (1982) y al ejemplar particular de la misma especie, sin ningún dato arqueológico en él. Otro subgrupo asocia únicamente los dos casos disponibles de Vicugna vicugna y el promedio tomado de Kent (1982), sin datos arqueológicos. El tercer subgrupo relaciona los ejemplares de referencia para Lama guanicoe y al promedio para Lama glama (Kent 1982) con un caso arqueológico (sigla SI-1298). Por último, un subgrupo que sólo está constituido por dos casos arqueológicos (siglas SI-1554, SI-689) y, a corta distancia de similitud, no se asocian con ningún subgrupo de referencia (Figura 6.a). Los resultados que brinda el ACP mantienen la descripción antes realizada y en el gráfico puede observarse una gran separación entre los subgrupos de referencia y los especímenes arqueológicos SI-1554 y SI-689, los cuales podrían tratarse de ejemplares de gran tamaño (Figura 7.a).

Posteriormente se procede a trabajar considerando las variables V4/V5 en primeras falanges posteriores (NSP=7, Tabla 1.a). El fenograma muestra también cuatro subgrupos, uno representado por los ejemplares de referencia de Lama guanicoe, en el que se asocian los casos arqueológicos SI-2109, SI-107, SI-108 y SI-1401, y el promedio para Lama glama (Kent 1982). Otro subgrupo está constituido por el ejemplar de Vicugna vicugna de referencia sin casos arqueológicos. Un tercer subgrupo lo forman los representantes de la especie Lama glama con el ejemplar de Vicugna pacos disponible y los promedios tomados de Kent (1982) para el género Vicugna, sin casos arqueológicos. Por último, tres casos arqueológicos (sigla SI-864, SI-852, SI-1172) se vinculan entre sí, conformando un único bloque y sólo vinculado a una gran distancia de los datos de referencia para los género Lama y Vicugna (Figura 6.b). En el ACP se observan tres dispersiones, una correspondiente a los representantes de Lama guanicoe con los casos arqueológicos incluidos, y otra que engloba tanto a los representantes de Lama glama como a los del "grupo pequeño" de camélidos, sin diferenciación precisa entre ambos géneros. En este análisis, que muestran las mayores diferencias entre los datos, puede notarse que los especímenes arqueológicos mantienen la asociación antes descripta, y los tres casos no vinculados a los de referencia, vuelven aquí a mostrarse aún más alejados del resto de los subgrupos (Figura 7.b).

Segunda falange. Considerando todas las variables disponibles (V6 a V10), (Tabla 1.b), el análisis de similitud agrupa a los datos en tres grandes subgrupos. Por una parte, se distingue un subgrupo que incluye a los ejemplares de Lama glama con el promedio de Kent
(1982) para alpaca, sin datos arqueológicos. Un segundo subgrupo lo constituyen los casos de referencia para Vicugna vicugna y $V$. pacos con los promedios para el mismo género (Kent 1982), sin datos arqueológicos. Por último, aparecen los pertenecientes a Lama guanicoe con la totalidad (NSP=5) de los casos arqueológicos relacionados (Figura 6.c). Entre los ejemplares de guanacos aparece asociado el promedio para dicha especie y el promedio para la llama, ambos tomados de Kent (1982). Que el promedio actual de los datos de Kent para la llama se vincule a los guanacos, se podría relacionar con el hecho de que estos animales pertenecen al Instituto de Investigación La Raya en Perú y han sufrido fuertes procesos de selección y manipulación antrópica. Además, la mayoría de los ejemplares de llamas actuales del resto de la colección de referencia han sido tomados de pastores bolivianos que no realizan ningún tipo de selección en sus rebaños, y se ha notado que estos individuos son mucho más pequeños que las llamas de La Raya. Por ello también es que el grupo de llamas se vincula al "grupo pequeño" de camélidos. Sin embargo, debe destacarse que no se mezclan. En el ACP se observan dos grandes dispersiones. Mediante este análisis, que muestra las mayores diferencias, se agrupan por una parte los ejemplares de Lama glama próximos al "grupo pequeño" de camélidos y por otro lado, más distanciados, el conjunto de guanacos de referencia que incluye a los cinco casos arqueológicos (Figura 7.c).

Tercera falange. Considerando todas las variables disponibles (V11 a V14) (Tabla 1.c), en el fenograma puede observarse como resultado del análisis de similitud, cuatro subgrupos. Uno que asocia los ejemplares de referencia de Lama guanicoe, sin vinculación de casos arqueológicos. Otro, que agrupa los ejemplares de referencia actuales para Lama glama, sin casos arqueológicos. Otro subgrupo claramente definido por los camélidos del "grupo pequeño" (alpaca y vicuña) en el que se inserta un caso arqueológico (sigla SI-1512). Finalmente, aparece un subgrupo complejo que agrupa cuatro casos arqueológicos (siglas SI-855, SI-2521-2599, SI-301, SI-139) con los promedios de los ejemplares actuales tomados de Kent (1982) para llama y guanaco. Este último subgrupo merece un análisis en profundidad -ver Discusiones- (Figura 6.d). En cuanto al análisis de ACP el gráfico vuelve a mostrar cuatro grupos de dispersión. Aquí se observa una mayor diferenciación entre los casos arqueológicos (siglas SI-855, SI-2521-2599, SI-301, SI-139) vinculados a los promedios tomados de Kent (1982) de los ejemplares de referencia para el género Lama tanto silvestre como domésticos. También se muestra con mayor claridad la diferenciación entre el caso arqueológico (sigla SI-1512) asociado al "grupo pequeño" del "grupo grande" de camélidos tanto silvestre como doméstico (Figura 7.d).

Otro modo interesante de acercarse a los datos es considerar los porcentajes de los casos que resultaron 
asignados como silvestres y domésticos. De este modo, en San Ignacio, del total de la muestra (NSP=20), más del $45 \%$ corresponde a especies silvestres. Por su parte, en el mejor de los casos las especies domésticas suman más del 50\%. Es decir que todas las especies de camélidos sudamericanos (tanto domésticas como silvestres) podrían estar representadas en los conjuntos óseos de San Ignacio. Por otra parte, el grupo más grande de camélidos identificados, no asociado a los morfotipos llama y guanaco de referencia, es mayor que ellos en tamaño en más de un $10 \%$. Todos estos datos comprueban la presencia clara de cuatro subgrupos que podrían vincularse no sólo con al menos tres de las cuatro especies de camélidos sudamericanos, sino también con algunos morfotipos especializados de las especies domésticas.

\section{Tecnología cerámica}

Se llevó a cabo una clasificación tipológica general basada en similitudes estilísticas y formales. Se clasificaron los tiestos teniendo en cuenta tratamientos de superficie, decoración, formas específicas (Convención Nacional de Antropología 1966; Sanhueza y Falabella 2008), coloración de pastas y superficies relacionadas con la cocción (Orton et al. 1997; García Rosselló y Calvo Trias 2006). Se infirieron posibles funciones teniendo en cuenta la morfología y huellas de uso (para mayores detalles en lo metodológico ver Frigolé 2010).

Considerando dichos atributos, y de forma general, el total de la muestra $(\mathrm{N}=416)$ pudo clasificarse en tres grupos. Un primer grupo mayoritario, que se denominó "Agrelo-Calingasta" ( $\mathrm{N}=408)$ y que podría atribuirse a la tradición local del período Temprano-medio, ya que los tiestos presentan tratamientos que van del alisado al pulido, coloración gris-negro y decoración incisa o sobrerelieve (Canals Frau y Semper 1956, Lagiglia 2006/2007). Si se tiene en cuenta los resultados de cocciones experimentales realizadas con materias primas de la zona (Moyano et al. 2011) y la coloración que presentaban las pastas y superficies (Orton et al. 1997; García Rosselló y Calvo Trias 2006), se podría decir que la cerámica fue cocida en atmósfera reductora o incompleta.

En este grupo se identificaron contenedores no restringidos y restringidos independientes (Convención Nacional de Antropología 1966) y una variedad de atributos morfo-funcionales (distintos tipos de bordes, con diferentes labios y diversas bases y uniones) (ver porcentajes y dibujos técnicos de las distintas partes en Frigolé 2010:Tabla 8, Figuras:14-29), dichos atributos responden al repertorio tradicional de la cerámica Agrelo (Lagiglia 2006/2007). Este conjunto cerámico parecería haberse ajustado a distintos funciones, teniendo en cuenta: huellas de uso, diámetros de las bocas y partes específicas (Frigolé 2010:Tabla 9).

El segundo grupo fue llamado "Negro bruñido", está conformado por tiestos que remontan $(\mathrm{N}=5)$ y que presentan un color negro homogéneo, tanto en las superficies como en la pasta, las superficies externas se encuentran totalmente bruñidas y las internas alisadas. Se pudo reconstruir una parte de la silueta de un jarro de forma globular, con un cuello estrecho o gollete, que podría resultar útil para verter y transportar líquidos (Frigolé 2010:Tabla 9), podría haber cumplido una función ceremonial ya que las bocas estrechas son propicias para el sahumado.

1.a. Primera falange

\begin{tabular}{cccccccc}
\hline N & FPh & V1 & V2 & V3 & V4 & V5 & Asignación \\
\hline 1 & SI.1298 & - & 21,59 & 18,65 & - & - & guanaco andino \\
2 & SI.1554 & - & 23,70 & 21,15 & - & - & Ilama grande (carguera) \\
3 & SI.689 & - & 23,67 & 20,04 & - & - & Ilama grande (carguera) \\
4 & SI.2109 & - & - & - & 17,60 & 15,74 & guanaco andino \\
5 & SI.864 & - & - & - & 20,35 & 18,75 & Ilama grande (carguera) \\
6 & SI.107 & - & - & - & 18,54 & 17,37 & guanaco andino \\
7 & SI.1172 & - & - & - & 18,69 & 19,70 & Ilama grande (carguera) \\
8 & SI.1401 & - & - & - & 18,26 & 16,12 & guanaco andino \\
9 & SI.108 & - & - & - & 18,30 & 16,66 & guanaco andino \\
10 & SI.852 & - & - & - & 18,35 & 18,72 & Ilama grande (carguera) \\
\hline
\end{tabular}

1.b. Segunda falange

\begin{tabular}{clcccccc}
\hline $\mathrm{N}$ & \multicolumn{1}{c}{ SPh } & V6 & V7 & V8 & V9 & V10 & Asignación \\
\hline 1 & SI. 2522 & 42,60 & 19,30 & 14,95 & 17,97 & 15,77 & guanaco andino \\
2 & SI. 2523 & 39,29 & 18,28 & 15,49 & 17,10 & 15,54 & guanaco andino \\
3 & SI. 1254 & 39,08 & 20,02 & 13,85 & 17,46 & 14,44 & guanaco andino \\
4 & SI. 43 & 40,14 & 19,68 & 13,94 & 19,65 & 14,70 & guanaco andino \\
5 & SI. 1174 & 38,55 & 18,14 & 13,05 & 16,76 & 15,85 & guanaco andino \\
\hline
\end{tabular}

1.c. Tercera falange

\begin{tabular}{clccccc}
\hline N & \multicolumn{1}{c}{ TPh } & V11 & V12 & V13 & V14 & Asignación \\
\hline 1 & SI. 1512 & 11,36 & 11,42 & 12,12 & 19,67 & "grupo pequeño" \\
2 & SI. 855 & 12,93 & 11,69 & 15,95 & 22,86 & Ilama \\
3 & SI. 301 & 11,85 & 10,97 & 13,17 & 22,06 & Ilama \\
4 & SI. 2521-2599 & 12,94 & 12,53 & 16,09 & 24,72 & Ilama \\
5 & SI. 139 & 11,84 & 11,55 & 14,87 & 19,59 & Ilama \\
\hline
\end{tabular}

Tabla 1. Especímenes arqueológicos: elementos anatómicos, variables métricas y asignaciones taxonómicas.

Table 1. Archaeological specimens: anatomic elements, metric variables, and taxonomic assignations. 

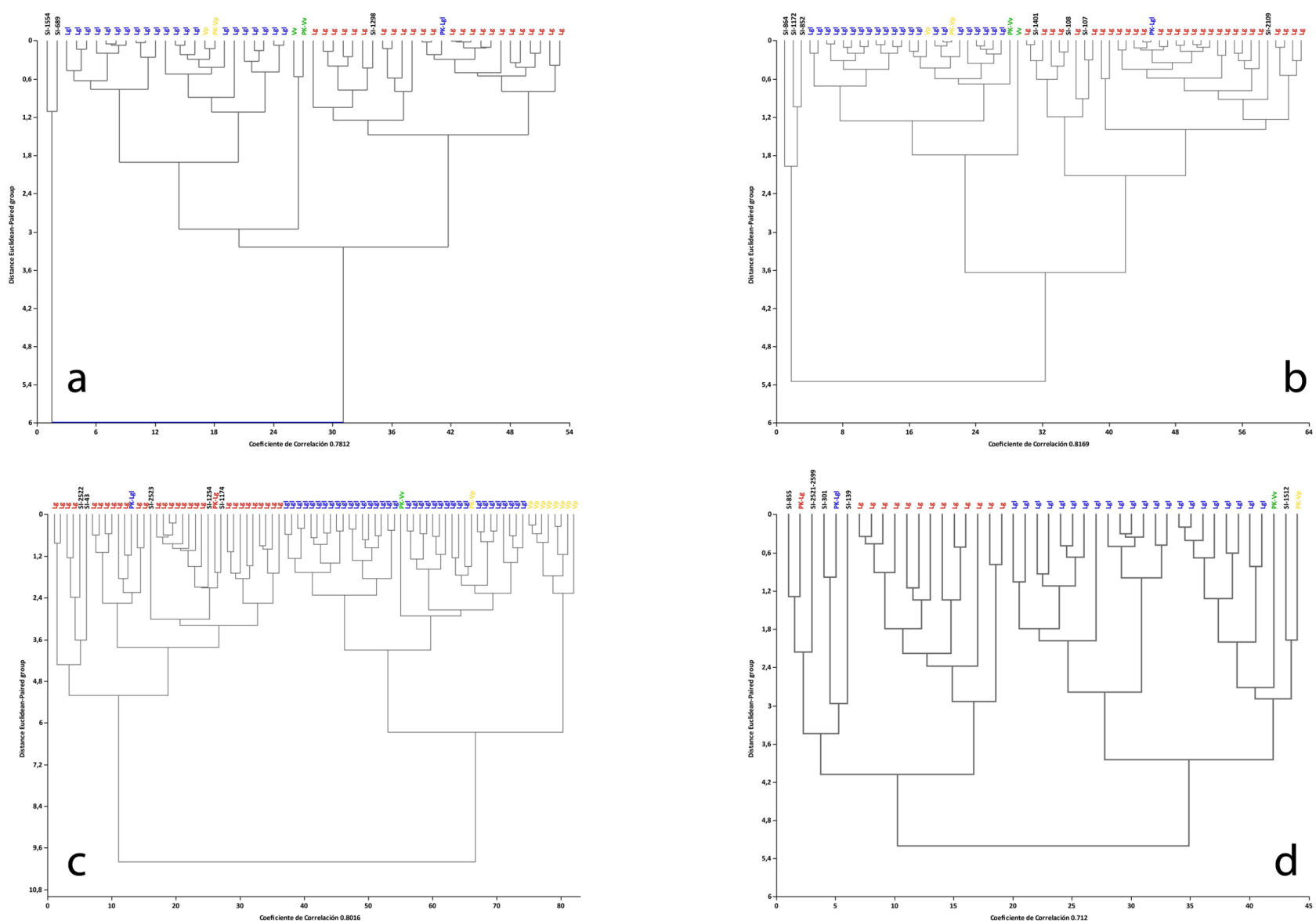

Figura 6. Fenograma (UPGMA) de relaciones de similitud. Lg: Lama guanicoe; Lgl: Lama glama; PK-Lgl: promedio por Kent (1982) para Lama glama; Vv: Vicugna vicugna; PK-Vv: promedio por Kent (1982) para Vicugna vicugna; Vp: Vicugna pacos; PK-Vp: promedio por Kent (1982) para Vicugna pacos. Los datos arqueológicos en negro y con número de sigla:a. Primera falange posterior (V2 y V3). b. Primera falange posterior (V4 y V5). c. Segunda falange completa (V6-V10). d. Tercera falange completa (V11-V14).

Figure 6. Phenogram (UPGMA) of similarity relationships. Lg: Lama guanicoe; Lgl: Lama glama; PK-Lgl: Kent's (1982) average for Lama glama; Vv: Vicugna vicugna; PK-Vv: Kent's (1982) average for Vicugna vicugna; Vp: Vicugna pacos; PK-Vp: Kent's (1982) average for Vicugna pacos. Archaeological data in bold, indicating catolog number: a. First fore phalange (V2 and V3). b. First fore phalange (V4 and V5). c. Complete second phalange (V6-V10). d. Complete third phalange (V11-V14).

Sólo tres fragmentos de cocción oxidante conforman el tercer grupo que se denominó "Rojo inciso", las superficies externas de dichos tiestos se hallan pintadas de rojo e incisas, y las superficies internas, pulidas. Dado la escasez y tamaño pequeño de estos fragmentos no pudieron inferirse formas.

Los tiestos clasificados como "Negro bruñido" y "Rojo inciso", presentan atributos que guardan similitud con la cerámica de los complejos que tuvieron su desarrollo en la vertiente occidental de Los Andes, durante el PAT. La técnica del bruñido y la aplicación de pintura, no han sido identificadas como propias de Agrelo; no obstante, los pulidos rojos y el bruñido se consideran diagnósticos de las vasijas El Molle, complejo que tuvo su desarrollo para los mismos períodos en el Norte semiárido de Chile. La pintura roja y las incisiones geométricas sobre cerámica pintada roja también podrían ser consideradas diagnósticas de tradiciones de la zona central de Chile, ya que la aparición de esta técnica en la cerámica de sitios Bato y Llolleo, del interior y de la costa, es recurrente

\section{(Sanhueza 2004).}

Si bien no se ha decidido incluir análisis de pasta en este trabajo (ya que sólo se presenta una clasificación tipológica basada en similitudes formales y estilísticas), se debe tener en cuenta que en trabajos anteriores (Frigolé 2010) se pudo observar, en lupa binocular (10x-60x), que las pastas presentaban diferencias en el tamaño de los áridos (siendo más finos las de los grupos "Negro bruñido" y "Rojo inciso"), en densidad (con porcentajes más altos para el grupo "Agrelo-Calingasta"), y dureza (los tiestos "Negro bruñido" y "Rojo inciso" resultaron en general más duros). Actualmente se están realizando análisis químicos (EAA) y de petrografía para identificar la naturaleza de los áridos.

Secuencia de reducción lítica y procedencia de materias primas

Desde un enfoque de la organización tecnológica (Nelson 1991), de sistemas de producción (Ericson 

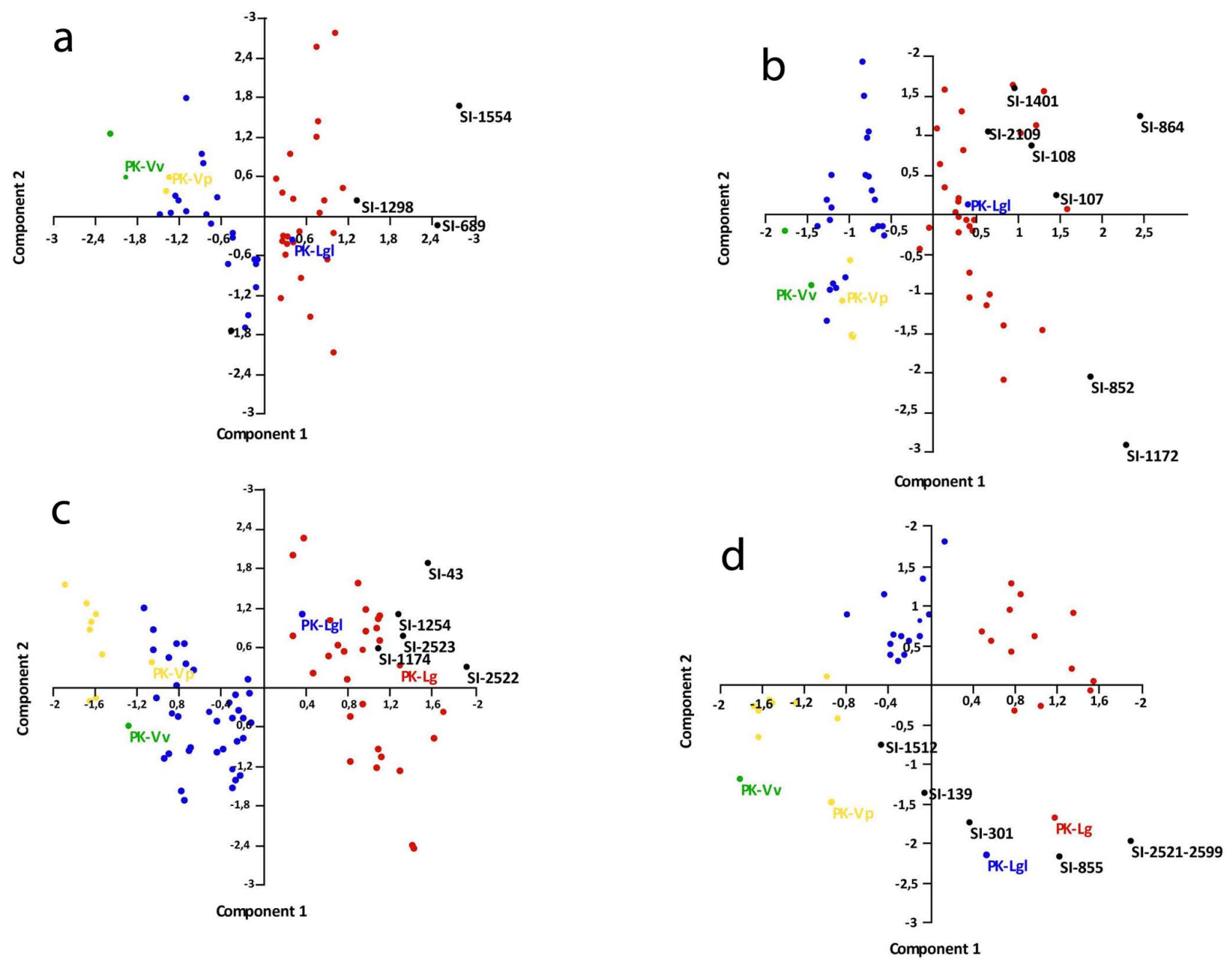

Figura 7. Gráfico de análisis de componentes principales. Lg: Lama guanicoe; Lgl: Lama glama; PK-Lgl: promedio por Kent (1982) para Lama glama; Vv: Vicugna vicugna; PK-Vv: promedio por Kent (1982) para Vicugna vicugna; Vp: Vicugna pacos; PK-Vp: promedio por Kent (1982) para Vicugna pacos. Los datos arqueológicos con número de sigla: a. Primera falange posterior (V2 y V3). b. Primera falange posterior (V4 y V5). c. Segunda falange completa (V6-V10). d. Tercera falange (V11-V14).

Figure 7. Scatterplot of principal component analysis. Lg: Lama guanicoe; Lgl: Lama glama; PK-Lgl: Kent's (1982) average for Lama glama; Vv: Vicugna vicugna; PK-Vv: Kent's (1982) average for Vicugna vicugna; Vp: Vicugna pacos; PK-Vp: Kent's (1982) average for Vicugna pacos. Archaeological data in bold, indicating catolog number: a. First fore phalange (V2 and V3). b. First fore phalange (V4 and V5). c. Complete second phalange (V6-V10). d. Complete third phalange (V11-V14).

1984), y teniendo en cuenta atributos morfológicos y tecno-tipológicos (Aschero 1983; Tixier et al.1980), en la muestra lítica del sitio $(\mathrm{N}=942)$, se registraron todas las etapas de la secuencia de reducción excepto el Mantenimiento. La mayoría de las piezas corresponden a las etapas de Talla $2^{\circ}(56 \%)$, Formatización (21\%) y Talla $1^{\circ}(17,8 \%)$. Su importante representación, y la presencia de piezas indiferenciadas $(2,4 \%)$, podrían indicar la ejecución de actividades de talla orientadas a la búsqueda de soportes y a la formatización de instrumentos. La Preparación (1,5\%) se evidencia en la presencia de núcleos elaborados sobre riolitas y cuarcitas locales del Valle de Potrerillos. Los instrumentos están escasamente representados (0,9\%). Casi su totalidad está confeccionada en materias primas del valle, sólo uno específicamente corresponde a un subtipo de riolita presente en la cantera cercana precordillerana de Los
Conitos. El conjunto está integrado principalmente por artefactos expeditivos de tamaño mediano y grande. Los tipos de artefactos son tres unifaciales, tres cuchillos, dos raspadores y un lito modificado por uso.

De esta manera, la explotación de recursos líticos indica un aprovisionamiento principalmente de materias primas disponibles en el Valle de Potrerillos (90\%). Se trata de riolitas, cuarcitas, cuarzos y granitos de calidad para la talla, pero cuyas características cumplirían con las exigencias necesarias para la elaboración de los instrumentos presentes en el registro con escasos requerimientos técnicos. Los recursos provenientes de la Cantera Los Conitos $(6,7 \%)$ y de la Cordillera $(4 \%)$ se encuentran representados casi exclusivamente en las etapas de formatización de soportes. La obtención de materiales provenientes de estas áreas más alejadas 
estaría vinculada a una probable explotación estacional de ciertos ambientes.

Otros litos presentes corresponde a instrumental de molienda que aparecen tanto en el interior de la estructura habitacional como en el exterior. Se identificaron en campo más de 12 moletas y tres molinos asociados a variados y numerosos cantos rodados, guijarros y núcleos a lo largo de todos los niveles. Cabe destacar que uno de los molinos presenta indicios de procesamiento de pigmentos.

\section{Discusiones}

\section{"Grupo pequeño" de camélidos}

En la Tabla 1.c puede observarse la presencia de un ejemplar arqueológico (sigla SI-1512) asignado al "grupo pequeño" de camélidos. Con los datos disponibles hasta el momento, es arriesgado intentar determinar con mayor exactitud su asignación taxonómica a nivel de especie. Como es el único caso del total de la muestra analizada $(\mathrm{NSP}=20)$ que da como resultado esta asociación taxonómica, podría suponerse que represente algún tipo de error. Sin embargo, se descarta la posibilidad de error por alteración del resto arqueológico en cuanto a termo-alteraciones, patologías y madurez ósea. En consecuencia, no se descarta la posibilidad de que se trate de un ejemplar pequeño por variabilidad intra-individuo, entonces quedaría aplicar otras clases de análisis para afirmar o negar la asignación establecida. Sin embargo, y considerando la posible presencia del "grupo pequeño" en el sitio, se evalúan a continuación las consideraciones.

Por una parte, este caso arqueológico podría vincularse más al espécimen silvestre del género Vicugna, cuya distribución actual tiene como límite austral la Reserva San Guillermo en la provincia de San Juan. No obstante, su presencia en el sitio pudo deberse a la caza del animal en ambientes de altura (Precordillera) lo cual implicaría una distribución más extensa hacia el sur en el pasado. Existe evidencia de la explotación de este animal en el norte precordillerano de Mendoza (Agua de la Cueva, sector sur, capa 2 b), aunque para un período más temprano, entre 11000 y 9000 años AP (García 1999:14). Por otra parte, se debería contemplar la posibilidad de existencia de redes de intercambio mediante las cuales se podría haber obtenido el cuero de las vicuñas. Las falanges habrían ingresado al contexto del sitio adheridas al cuero (Marean y Cleghorn 2003:19; O'Connell et al. 1988:126). Además, el uso de su fibra está documentado para momentos más tardíos (650 y 1050 D.C.) en el Valle de Iglesia, norte de San Juan (Michieli 2001:26).

Por otra parte, y por el momento, se descartaría la posibilidad de que correspondiera a un individuo doméstico (alpaca) dado que este animal precisa un ambiente específico de bofedales para su óptimo rendimiento -mayor producción y calidad de lana-
(Browman 1990:338). Además, no existen referencias biológicas, etnográficas, ni arqueológicas que muestren la presencia de esta especie en ambientes similares al de estudio, considerado inapropiado según los requerimientos del animal. En contraposición, existen datos actuales y arqueológicos para la puna seca boliviana sobre la presencia de este camélido habitando ambientes considerados no óptimos, pero que con la intervención humana se transforman en habitables y de alto rendimiento (Reiner y Bryant 1986; Pokines 2011). Además, en la vertiente occidental de la puna de Atacama, en el sitio Tulán-54 (Formativo Temprano ca. 3200$2300{ }^{14} \mathrm{C}$ A.P.), se ha registrado la presencia de incisivos y fibra con morfología atribuible a alpaca (Cartajena 2009; Nuñez et al. 2006). Sin embargo, cabría al menos mencionar la posibilidad de que este tipo de camélido haya entrado al sitio como producto de intercambios. Sin embargo, lo expuesto queda meramente en el plano de lo especulativo, planteando la necesidad de continuar con las investigaciones a fin de precisar los resultados obtenidos hasta el momento. En cualquier caso, correspondiese al ejemplar doméstico o silvestre, su manejo estaría vinculado a la utilización de lana para la confección de textiles, ya que ambas especies son valoradas por sus fibras de excelente calidad -liviandad, finura, suavidad- (Cardozo Gonzáles 2007:85).

Para mejorar la asignación mediante el uso de la osteometría, se deberían ampliar y precisar las muestras de referencia en función de las especies y subespecies esperables para la región de estudio. Es decir, que para el caso de la vicuña se debería trabajar con colecciones de referencia de la subespecie Vicugna vicugna vicugna, ya que ésta es la más grande y se distribuye en la zona sur de Los Andes (Wheeler y Laker 2009 y citas en él). Para la alpaca se debería ampliar la muestra, dada la gran manipulación fenotípica y genética que ha sufrido, con lo cual se ha generado un gran rango de variabilidad métrica (Kent 1982). Además se debería aplicar la osteometría sobre otros huesos del esqueleto postcraneal del mismo sitio, a fin de determinar si más elementos brindan esta misma asignación taxonómica. Por otra parte, pueden también realizarse estudios de ADN para precisar dicha asignación.

\section{"Grupo grande" de camélidos}

Dentro de este grupo se ha determinado la presencia de tres morfotipos de camélidos: uno asociado a los guanacos; el segundo vinculado a los promedios para llama y guanaco presentados por Kent (1982), y otro, separado notablemente de los datos de referencia, de gran tamaño (Tabla 1).

La presencia del morfotipo guanaco en el sitio (NSP=10) se vincula al empleo de material comparativo actual reducido geográficamente al denominado grupo "guanaco andino". Al exceptuar el "guanaco patagónico" se disminuye el margen de error, dado por el mayor rango de 
variabilidad que manifiesta esta especie silvestre a lo largo de todos Los Andes. El "guanaco andino" se caracteriza por ser más pequeño en tamaño que el "patagónico" (Mengoni y Yacobaccio 2006, entre otros). Los ejemplares de guanacos disponibles en la referencia utilizada han servido para ajustar el gradiente de tamaño, por ser los más próximos geográficamente al sitio (procedentes del norte de Mendoza y San Juan) y también en lo que respecta a las subespecies. La presencia de esta especie silvestre en San Ignacio demostraría la continuidad de la caza como actividad económica en la utilización de recursos naturales disponibles.

Con respecto al segundo morfotipo de camélido "grande" detectado, cabe considerar que los datos de referencia que emplea Kent (1982) en su investigación, para el caso del guanaco, corresponden a individuos del morfotipo "guanaco patagónico", tomados tanto de Chile como de Argentina. Por ello es que presenta a dicha especie como el camélido más grande en el esquema de gradiente de tamaño para todos los camélidos sudamericanos. Por otra parte, con Lama glama sucede algo similar, ya que las llamas que emplea son más grande en tamaño por lo que han sido fuertemente seleccionadas y manipuladas dentro del Instituto de donde proceden, y más aún si son comparadas con los datos actuales de referencia considerados aquí que pertenecen a pequeños pastores de Khonkho Wankane, Bolivia.

Aclarado lo anterior, sólo resta interpretar los casos arqueológicos, vinculados a dichos promedios, como individuos pertenecientes a animales domésticos, dado que el único caso de animal silvestre tan grande correspondería al morfotipo "guanaco patagónico", que no aparece en esta región de estudio. Aunque no se vinculen directamente estos especímenes arqueológicos con los datos de referencia que se poseen para Lama glama, puede inferirse que se trata de individuos domésticos del género Lama seleccionados antrópicamente. Además, es necesario resaltar que existe una gran variabilidad en el tamaño de dicha especie doméstica, y que ésta se ve reflejada en un gradiente de tamaño corporal de norte a sur, que parte desde Ecuador con las llamas más pequeñas (Miller y Gill 1990).

No obstante, y ante la destacada posibilidad de que se traten de animales domésticos, es ampliamente reconocido que la llama es un valioso animal doméstico, que brinda abundantes y variados recursos: lana, carne, cuero y fuerza motriz; además de su uso vinculado a lo ritual (Mengoni 1991). Todos estos recursos pudieron ser explotados al mismo tiempo por el grupo que habitó en San Ignacio durante el desarrollo de sus variadas actividades domésticas.

Por último, el tercer morfotipo de camélido "grande" establecido por osteometría, con aproximadamente un $10 \%$ más en el tamaño que los antes descriptos, puede explicarse al descartar la posibilidad de hallar el morfotipo "guanaco patagónico" en la región y al incorporar en el debate la manipulación reproductiva, fenotípica y prácticas de manejo y control de rebaños de animales domésticos como la llama. De este modo, no queda espacio para camélidos silvestres tan grandes documentados en el área de estudio, y a través de la manipulación antrópica pueden generarse morfotipos especializados, como por ejemplo las denominadas "llamas cargueras".

Estudios biológicos y etnográficos han demostrado que en el manejo de rebaños una de las técnicas más difundidas para controlar el crecimiento y reproducción de la manada es la castración de machos. Esta actividad constituye la única vía de selección y control (desviación de la conducta agresiva) de rebaños, y de esta forma los machos castrados, las hembras y las crías se mantienen juntos a lo largo del año (Cardozo Gonzáles 2007:124; Göbel 2001:103-104; Rocha 2004:273). Las modificaciones óseas que se generan en el esqueleto de los mamíferos por causa de esta práctica, es el aumento en el crecimiento de la longitud (alrededor del 10\%) de los huesos largos especialmente (Fowler 1998:136). Este crecimiento fue demostrado osteométricamente en estudios de huesos largos (e.g. metacarpo y metatarso) de ovejas (Davis 2000:862).

Por otra parte, estudios etnográficos sostienen que la mayoría de las caravanas están compuestas por machos castrados dado que son más altos, más fuertes o resistentes y más dóciles (Browman 1990:398; Nielsen 2001:168; Tomka 1992:427; entre otros) y comúnmente son los que dirigen la caravana (Cardozo Gonzáles 2007:85). Una llama carguera puede servir para los viajes hasta los 10 o 12 años de edad. Luego, en función al rendimiento del animal, esta llama es sacrificada y se aprovechan los huesos (para instrumentos, por ser fuertes y más grandes); la fibra (para sogas, hondas y costales, por ser más resistentes) y la carne (como charqui por su dureza), (Paz Flores 2000:136-137).

Frente a lo expuesto, queda manifestada la gran posibilidad de que en el sitio, los habitantes hayan desarrollado actividades vinculadas al manejo de animales domésticos (llamas) no solo con las denominadas "intermedias" (aprovechamiento variado de sus recursos) sino también con las de morfotipo específico de gran tamaño para carga.

Entonces puede sostenerse que los grupos humanos que poblaron San Ignacio hacían uso de camélidos "grandes" tanto silvestres (guanacos NSP=10) como domésticos (llamas NSP=4), con algunos morfotipos especializados de estos últimos (NSP=5), lo cual actuaría como estrategia minimizadora del riesgo (Yacobaccio et al. 1998). Con respecto al "grupo pequeño" de camélidos (NSP=1), aunque su representación es escasa, 
se sugiere continuar con los estudios a fin de precisar dicha asignación taxonómica y, de momento, se sugiere su aprovechamiento vinculado al uso de sus fibras.

\section{Otros materiales: cerámico y lítico}

El conjunto cerámico clasificado como"Agrelo-Calingasta" pudo haberse confeccionado en el mismo sitio, dado su similitud formal y estilística con la cerámica de tradición local, la disponibilidad de arcillas locales de buena calidad (Moyano et al. 2010), y la presencia de los hornillos que pudieron ser empleados para su cochura, el excremento tomado de los animales domésticos pudo ser utilizado como combustible, entre otros insumos. La presencia de atributos morfo-funcionales variados y huellas de uso podrían evidenciar que las vasijas fueron usadas para distintas actividades domésticas (como servir, preparar y cocinar). Este conjunto de elementos constituye un indicador más para la caracterización del sitio como de uso permanente y una planificación de la ocupación prolongada.

Los grupos "Negro bruñido" y "Rojo inciso" guardan similitud estilística con la cerámica de complejos del norte semiárido y la región central de Chile. Las inferencias que se pudieron realizar acerca de la forma que pudo tener la vasija negro-bruñida, podrían atestiguar un uso de la alfarería no vinculado exclusivamente a lo doméstico, como el uso ritual del sahumado. Estudios etnográficos realizados en comunidades alfareras y pastoriles de Jujuy señalan que formas similares se usan para rociar chuia sobre el rebaño durante la señalada (Menacho 2007), lo que podría vincularse con la presencia de animales domésticos en el sitio establecida por osteometría, sin embargo al no haber reconstruido la totalidad de la forma y no tener certeza de su tamaño, se deberán realizar análisis de contenidos para confirmar estas posibilidades.

La forma que pudo ser identificada en parte en el grupo "Negro bruñido" podría ser similar a algunas formas que se encuentran dentro del repertorio variado del Complejo El Molle, en el marco del cual vasijas restringidas independientes con golletes y de contornos complejos han sido halladas en la cuenca del río Limarí, en el norte semiárido de Chile (Niemeyer et al. 1989). En Malargüe, al sur de Mendoza, se hallaron vasijas con formas similares que remiten a tradiciones alfareras provenientes de Chile (Lagiglia 2005).

Los pobladores del valle contaban con materia prima de calidad en las proximidades del asentamiento, además de una tradición alfarera local de larga data, por lo que parece claro que el obtener contenedores cerámicos por intercambio no responde a necesidades cotidianas. Se podría plantear entonces, cómo hipótesis, que la cerámica que se supone de tradición alóctona haya sido un bien de prestigio (Stark 1999) que circulaba junto a otros bienes en una red extra-regional, como al parecer sucedió en las aldeas de altura del sur de Mendoza (Neme 2007), esta posibilidad deberá explorarse con mayor profundidad en trabajos futuros. Otra evidencia sobre el posible intercambio entre poblaciones de ambas vertientes cordilleranas es el hallazgo de media cuenta de molusco proveniente del Pacífico, en la Cantera Los Conitos, explotada por los habitantes del Valle de Potrerillos para la extracción de materias primas líticas (Cortegoso 2004).

No obstante la propuesta anterior, no se descarta que la cerámica negra bruñida y roja incisa pudiera haber sido fabricada localmente, siguiendo patrones en los "modos de hacer" similares a los de complejos cerámicos de la vertiente occidental. El conocimiento sobre cómo reproducir estas formas debió entonces resultar de procesos migratorios que posibilitaron la transmisión entre los pobladores de ambos lados de la Cordillera, o bien podría tratarse de "vasijas colaborativas" (Crown 2007) entre alfareros migrantes. Reproducir estas vasijas no habría sido un problema ya que localmente se contaba con materia prima disponible (Moyano et al. 2010), además de pigmentos rojos hallados en la unidad habitacional de San Ignacio como en las estudiadas en la otra margen del río Mendoza (Cortegoso 2006).

El repertorio de material lítico de carácter expeditivo evidencia la realización de diversas actividades domésticas que no demandaron la confección de herramientas especializadas. Están representadas casi todas las etapas de la secuencia de reducción lítica dentro de la casa-pozo. La ausencia de mantenimiento en el instrumental lítico y la escasa regularización del mismo, pueden relacionarse con la amplia disponibilidad de materias primas de buena calidad locales, con su bajo constreñimiento en tiempo y en demandas funcionales.

Por otra parte, el empleo de materias primas procedentes de Cordillera podría ser indicador de la explotación de sitios en ambientes de altura. En estos sitios, de actividades estacionales con cronología sincrónica a San Ignacio (e.g. Resguardo de La Manga) aparecen altamente representados los instrumentos, siendo en su mayoría puntas de proyectil fracturadas (Cortegoso 2006). En contraste, la ausencia de dichos instrumentos en el contexto doméstico de San Ignacio, podría contribuir a categorizarlo como un sitio de asentamiento permanente inserto en un circuito de movilidad amplio, en donde se hubiesen seleccionado sitios estacionales para actividades específicas (e.g. caza de guanacos, aprovechamientos de pasturas, adquisición de materas primas, etc) que demandan instrumentos con requerimientos técnicos más complejos. El conjunto lítico analizado responde al menor riesgo involucrado en la ejecución de actividades en sistemas económicos que diversifican o amplían la base de la subsistencia.

\section{Conclusiones}

Este trabajo se efectuó con el objeto de presentar y 
caracterizar el sitio San Ignacio, inédito para la región y aportar información a la historia cultural sobre el uso humano del Valle de Potrerillos entre los siglos III y VIII de nuestra era. Se establecieron las diversas actividades llevadas a cabo por los habitantes de este contexto doméstico, mediante el análisis osteométrico, el estudio de la secuencia de reducción lítica, de procedencia de materias primas y el análisis morfo-funcional cerámico.

El ambiente en donde se localiza San Ignacio cuenta con abundantes recursos faunísticos, botánicos y abióticos. Tal disponibilidad de recursos sumada a la presencia permanente de agua y al clima templado predominante hicieron del valle un área atractiva para el asentamiento de grupos humanos. Las características que presenta el sitio en cuanto a estructuras y materiales asociados se correlacionan con el patrón establecido por Kent (1992) para sitios en que sus habitantes planificaron una ocupación de largo plazo.

En el conjunto de datos arqueozoológico aparecen representados diferentes morfotipos de camélidos sudamericanos, tanto silvestres como domésticos. Además, surge la posibilidad de evidencia material para un morfotipo especializado de camélido doméstico. Los porcentajes en la identificación específica logrados demostrarían que los camélidos silvestres aportaron más a la subsistencia, en lo que respecta a recursos cárnicos, de lo que se podría suponer. Las prácticas de caza pudieron realizarse en otros sitios de altura de uso estacional. Frente a esta posibilidad, los rebaños de animales domésticos podrían haberse mantenido "en pie" para contrarrestar el riesgo y aprovechar otros productos como: lana, excremento, fuerza motriz y posteriormente cueros y charqui. La presencia de un morfotipo de camélido de gran porte, indicaría la manipulación fenotípica y la práctica especializada de manejo de rebaños no sólo en lo referido a la reproducción y control del mismo, sino también a la generación de unidades de trasporte.

Los patrones de movilidad a corta, media y larga distancia en la región, estarían evidenciados por la explotación de materias primas líticas y arcillas procedentes del mismo valle, de Precordillera y Cordillera, además de la caza de guanacos y vicuñas en dichos ambientes. Por otra parte, la presencia de cerámica similar a la de los complejos de la vertiente occidental de Los Andes podría estar indicando la interacción (intercambio y/o migración) entre sociedades que habitaron uno y otro lado de la Cordillera.

En síntesis, San Ignacio constituiría un sitio de ocupación permanente por grupos humanos que practicaron una economía combinada de producción y extracción de recursos faunísticos y botánicos. La caza de guanacos aportó más a la dieta de lo que se pensaba en sociedades productoras; se presupone que el manejo y control de animales domésticos se vincularía a la reducción del riesgo y a la explotación de sus productos secundarios.
La presencia de cultivos en el interior de la unidad doméstica da cuenta de su empleo, y posiblemente de su producción. El instrumental lítico elaborado principalmente sobre materias primas locales y de escasa regularización, evidenciarían un uso expeditivo vinculado a la alta disponibilidad de material. Además, los artefactos líticos como raspadores, cuchillos, moletas y molinos implicarían diversas actividades domésticas asociadas a la preparación de alimentos, cueros y de minerales. La presencia, en el conjunto cerámico, de atributos morfofuncionales variados y huellas de uso podrían evidenciar que las vasijas fueron usadas para distintas actividades domésticas (como servir, preparar y cocinar). Estos grupos agroalfareros poseían una movilidad de tipo logística que explotó estacionalmente ambientes de altura, y se relacionaron con sociedades del otro lado de la vertiente cordillerana y/o de los valles interandinos al norte.

El registro arqueológico aquí estudiado corresponde a un espacio restringido (interior de una casa-pozo) que fue obtenido mediante intervenciones de rescate. Pese a ello, los resultados alcanzados dan cuenta de ciertas actividades domésticas y de las estrategias de subsistencia desarrolladas por un grupo humano con un repertorio material similar al de las sociedades agro-ganaderas que habitaban los valles de Calingasta e Iglesia (San Juan).

Se espera que los datos aquí vertidos, mediante el abordaje integrador de diferentes materiales y la aplicación de técnicas novedosas para la región, constituyan verdaderos aportes en apoyo a las investigaciones emprendidas en el área. Además de contribuir con información relevante para una futura discusión y confrontación de los modelos regionales planteados (Cortegoso 2004; Gambier 2000). Lo presentado es sólo una primera aproximación sobre la compleja realidad cultural que tuvo lugar en San Ignacio durante el período Agro-alfarero Temprano-Medio regional.

Mendoza, 24 de mayo 2011

\section{Agradecimientos}

Las investigaciones sintetizadas aquí forman parte del Programa de Investigación y Desarrollo de la Universidad Nacional de Cuyo (ResN453/2010) y de un proyecto de la Agencia Nacional de Promoción Científica y Tecnológica (PICT-2006-N421), bajo la dirección del Dr. Durán. Estos estudios se realizaron con el apoyo de CONICET y APCyT. Se agradece a los Dres. Víctor Durán y Valeria Cortegoso su incondicional apoyo y el esfuerzo brindado en las lecturas críticas del manuscrito, sin embargo los autores son los únicos responsables de los errores u omisiones.

\section{Bibliografía}

AAVV. 1966. $1^{a}$ Convención Nacional de Antropología, pp.121-152, Universidad Nacional de Córdoba, Dirección General de Publicaciones, Carlos Paz. 
Aschero, C. 1976 y rev. 1983. Ensayo para una clasificación morfológica de artefactos líticos. Informe a CONICET, MS.

Behrensmeyer, A. 1978. Taphonomic and Ecologic information from bone weathering. Paleobiology 4:150-162.

Belloti López de Medina, C. 2007. "Zooarqueología del sitio Soria 2 (Depto. de Santa María. Pcia. de Catamarca) y estudio comparativo del registro zooarqueológico del sur de los Valles Calchaquíes. Para los períodos Formativo y Desarrollos Regionales (siglos I a.C. a XV D.C.)".Tesis de Licenciatura. Universidad de Buenos Aires. F.F.yL. Departamento de Antropología. MS.

Browman, D. 1990. High Altitude Camelid Pastoralism of the Andes. En: J. Galtay y D. Johnson (eds.), The World of Pastoralism: Herding Systems in Comparative Perspective, cap11, pp.323-352, Guilford, New York.

Canals Frau, S. y J. Semper. 1956. La Cultura de Agrelo (Prov. de Mendoza). Runa VII (2):160-187. Buenos Aires.

Cardich A. y A. Izeta. 1999-2000. Revisitando Huargo (Perú). Análisis cuantitativos aplicados al análisis a restos de Camelidae del Pleistoceno Tardío. Anales de Arqueología y Etnología 54:29-40.

Cardozo Gonzáles, A. 2007. Camélidos (Versión revisada y ampliada de la obra original "Auquénidos" de A. Cardozo-1954), pp.466. Centro de Investigación en forrajes "La Violeta". Departamento de Fitotecnia-FCAyP-UMSS, Bolivia.

Cartagena, I. 2002. "Los conjuntos arqueofaunísticos del Arcaico Temprano en la Puna de Atacama, Norte de Chile". Tesis doctoral. Freie Universität Berlin. ABESY Vertriebs $\mathrm{GmbH}$, Germany. MS.

Cartagena, I. 2009. La variabilidad morfométrica del conjunto de camélidos pequeños durante el Arcaico Tardío y el Formativo Temprano en Quebrada Tulán, norte de Chile. Revista del Museo de Antropología 2:199-212.

Cortegoso, V. 2004. Organización Tecnológica: explotación de recursos líticos y el cambio en la subsistencia de cazadores a agricultores en el N.O de Mendoza. Facultad de Ciencias Naturales y Museo, Universidad Nacional de La Plata, pp.454. MS.

Cortegoso, V. 2006. Comunidades agrícolas en el Valle de Potrerillos (NO de Mendoza) durante el Holoceno Tardío: organización de la tecnología y vivienda. Intersecciones en Antropología, 7:77-94.

Cortegoso, V. 2008. Disponibilidad de recursos líticos en el noroeste de Mendoza: cambios en la organización tecnológica en la cuenca del río Blanco. CazadoresRecolectores del Cono Sur, 3:95-112.
Crown, P. 2007. Life Histories of Pots and Potters: Situating the Individual in Archaeology. American Antiquity, 72(4):677-690.

Davis, S. 2000. The Effect of Castration and Age on the Development of the Shetland Sheep Skeleton and a Metric Comparison Between Bones of Males. Journal of Archaeological Science, 27:373-390.

Durán, V.; V. Cortegoso; H. Chiavazza; H. Lagiglia y A. García. 2002. Proyecto Potrerillos -Fase II- Relevamiento y Rescate Arqueológico en el Área del Emprendimiento. Informe Final, pp.78, Instituto de Estudios, Asesoramiento y Servicios (IDEAS). Facultad de Filosofía y Letras. Universidad Nacional de Cuyo. Mendoza. MS.

Ericson, J. 1984. Toward the analysis of lithic production systems. En: J. Ericson y B. Purdy (eds.), Prehistoric Quarries and Lithic Production, pp.1-19, University Press, Cambridge.

Fowler, M. 1998. Medicine and Surgery of South American Camelids: Llama, Alpaca, Vicuña, Guanaco. 2nd ed. lowa State University Press, Ames, Iowa.

Frigolé, C. 2010. "Análisis del conjunto cerámico de San Ignacio (Potrerillos). Estrategias de subsistencia y movilidad". Tesis de Licenciatura. F.F.yL., U.N.Cuyo. Mendoza. MS.

Gambier, M. 1977. La Cultura de Ansilta. Instituto de Investigaciones Arqueológicas y Museo. Facultad de Filosofía, Humanidades y Arte. Universidad Nacional de San Juan. San Juan. pp. 272.

1988 La Fase Cultural Punta del Barro. Instituto de Investigaciones Arqueológicas y Museo. F.F.H.yA. Universidad Nacional de San Juan. San Juan. pp. 197.

Gambier, M. 2000 Prehistoria de San Juan, Segunda Edición, Ansilta, San Juan.

García, A. 1994. Nuevas Perspectivas para el estudio de la cultura de Agrelo. Revista del Centro Interdisciplinario de Estudios Regionales, 12:19-27.

García Rosselló J. y M. Calvo Trias. 2006. Análisis de las evidencias macroscópicas de cocción en la cerámica prehistórica: una propuesta para su estudio. Mayurqa 31: 83-112.

Gasco, A. y E. Marsh. 2011. Species Differentiation of Camelidae at Khonkho Wankane: An Osteometric Study of the First Phalange. En: J. Janusek (ed.), Early Complexity in the South-Central Andes: Khonkho Wankane and its Hinterland (Archaeology in the Machaca Region of Bolivia, Volume I), Instituto Cotsen, Los Ángeles, EEUU. En prensa.

Gasco, A., C. Frigolé; S. Castro; R. Moyano y C. Privitera. 2010. Acercamiento a un contexto doméstico 
agroalfarero mendocino. Un aporte integrados desde diferentes metodologías. En: Actas del XVII Congreso Nacional de Arqueología Argentina, Mendoza.

Göbel, B. 2001. El ciclo anual de la producción pastoril en Huancar (Jujuy, Argentina). En: G. Mengoni, D. Olivera y $\mathrm{H}$. Yacobaccio (eds), El uso de los camélidos a través del tiempo, GZC-ICAZ-Ediciones del Tridente, Buenos Aires. pp.91-115.

González Díaz, E. y L. Fauqué. 1993. Geomorfología. En: V. Ramos (ed), XII Congreso Geológico Argentino. Geología y Recursos Naturales de Mendoza, Relatorio I(14):217-234. Mendoza.

Grant Lett-Brown, J. 2008. "El recurso Camelidae en sitios de la Puna Meridional Argentina: una aproximación osteométrica". Tesis de Licenciatura. Universidad de Buenos Aires, F.F.yL., Departamento de Ciencias Antropológicas. MS.

Hammer, Ø.; D. Harper y P. Ryan. 2001. P A S T : Palaeontological statistics software packager for education and data analysis, Palaeontologia Electronica 4(1):9.

Ingbar, E; M. L. Larson y B. Bradley. 1989. A Nontipological Approach to debitage Analysis. En: D. Amick y R. Mauldin (ed.), Experiments in Lithic Technology, pp.117-135. British Archaeological Reports. International Series: 528. Oxford

Izeta, A. 2007. Zooarqueología del sur de los valles Calchaquíes (Provincia de Tucumán y Catamarca, República Argentina). Estudio de conjuntos faunísticos del primer milenio A.D. BAR International Series S1612. oxford.

Izeta, A. 2009. Dossier: Osteometría de camélidos sudamericanos. Revista del Museo de Antropología, 2:125-126.

Izeta, A., C. Otaola y A. Gasco. 2009. Estándares métricos y variabilidad en falanges proximales de camélidos sudamericanos. Su importancia como conjunto comparativo para interpretaciones en arqueología. Revista del Museo de Antropología 2:169-180.

Johnson, A. W y T. Earle. 2003. La Evolución de las Sociedades. Desde los grupos cazadores-recolectores al estado agrario, cap.1, pp.39-45, Ariel, Barcelona.

Kelly, R. 1992. Mobilty/Sedentism: concepts, archaeological measures, and effects, Annu. Anthropology, An. Reviews Inc., 21:43-66.

Kent, J. 1982. "The domestication and exploitation of the South American camelids: methods of analysis and their application to circum-lacustrine archaeological sites in Bolivia and Peru", Departamento de Antropología,
Washington Universidad St. Louis, Missouri, pp.626.

Kent, S. 1992. Studying Variability in the Archaeological Record: An Ethnoarchaeological Model for Distinguishing Mobility Patterns. American Antiquity57:635-660.

Lagiglia, H. 2005. Bato-Llolleo en la Arqueología Argentina. Anales de Arqueología y Etnología, 59-60:69105.

Lagiglia, H. 2006/2007. Estudio Integral de la cultura Agrelo. Documento de uso interno del Laboratorio de Geo-Arqueología, U.N.Cuyo. pp.41. Mendoza. MS.

Marean, C. y N. Cleghorn. 2003. Large mammal skeletal element transport: applying foraging theory in a complex taphonomic system. Journal of Taphonomy 1:15-42.

McGuire, R. y M. Schiffer. 1983. A the ory of architectural design. Journal of Anthropological Archaeology 2:277-303.

Menacho, K. 2007. Etnoarqueología y estudios sobre funcionalidad cerámica: aportes a partir de un caso de estudio. Intersecciones en Intersecciones en Antropología, 8:149-161.

Menegaz, A., F. Goin y E. Jaureguizar. 1989. Análisis morfológico y morfométrico multivariado de los representantes fósiles y vivientes del género Lama (Artiodactyla, Camelidae). Sus implicancias sistemáticas, biogeográficas, ecológicas y biocronológicas. Ameghiniana, 26(3-4):153-172.

Mengoni G. 1991. La llama y sus productos primarios. Arqueología 1:179-196.

Mengoni, G. y H. Yacobaccio. 2006. The domestication of South American camelids: a view from the SouthCentral Andes. En: M. Zeder, D. Bradley, E. Emshwiller y B. Smith (eds.), Documenting Domestication: New Genetic and Archaeological Paradigms, cap.16, pp.228-244, Universidad of California, Berkeley.

Michielli, C. 2001. Textilería Aguada en el Valle de Iglesias, Provincia de San Juan. Publicaciones 24:23-42.

Miller, G. y A. Gil. 1990. Zooarchaeology at Prirncay, a Formative Period Site in Highland Ecuador. Journal of Field Archaeology, Vol.17(1):49-68.

Moyano, R.; C. Frigolé; L. Sammarco y C. Marquet. 2011. Reproducción experimental de procesos de manufactura de cerámica Agrelo: una propuesta metodológica. UNCuyo. Mendoza. MS.

Moyano, R.; M. C. Marquet y L. Sammarco. 2010. Tecnología cerámica: estudios experimentales sobre la 
cerámica del sitio arqueológico San Ignacio (Noroeste de Mendoza). En: Huellas... Búsquedas en Arte y Diseño. Nº, pp.30-38. FAD, U.N.Cuyo, Zeta Editores. Mendoza.

Nelson, M. 1991. The Study of Technological Organization. En: M. Schiffer (ed.), Archaeological Method and Theory, Vol.3:57-99, The University of Arizona Press, Tucson.

Neme, G. 2007. Procesos de adaptación humana en los ambientes de altura del sur de Mendoza. En: CazadoresRecolectores de altura en los Andes Meridionales: El Alto Valle del Río Atuel, cap.8, pp.121-140. British Archaeological Reports. International Series:1591, Archaeopress, Oxford.

Niemeyer, H., G. Castillo y M. Cervellino. 1989. Los Primeros Ceramistas del Norte Chico: Complejo El Molle (0 a 8000 D.C.). En: Hidalgo J., V. Schiappacasse, H. Niemeyer, C. Aldunate, e I. Solimano (eds.), Cultura de Chile. Prehistoria. Desde sus orígenes hasta los Albores de la Conquista, cap.10, pp.227-263, Andrés Bello, Santiago.

Nielsen, A. 2001. Ethnoarchaeological Perspectives on Caravan Trade in the South-Central Andes. En: L. Kuznar (ed), Ethnoarchaeology of Andean South America: Contributions to Archaeological Method and Theory, pp.163-201. Ethnoarchaeological Series Vol.4. International Monographs in Prehistory, Ann Arbor, Michigan.

Núñez, L., I. Cartajena, C. Carrasco, P. de Souza y M. Grosjean. 2006. Emergencia de comunidades pastoralistas formativas en el sureste de la Puna de Atacama. Estudios Atacameños 32: 93-117.

O'Connell, J., K. Hawkes y N. Jones. 1988. Hadza hunting, hutchering, and bone transport and their archaeological implications. Journal of Anthropological Research 44:113-161.

Orton, C., P. Tyers y A. Vince. 1997. La cerámica en Arqueología. Crítica, Barcelona.

Paz Flores, P. 2000. Los Ilameros de Qochauma y sus viajes a Markapata. En: Flores Ochoa, J. y Y. Kobayashi (eds), Pastores Altoandinos. Realidad, sacralidad y posibilidades, pp.135-148, Plural, Bolivia.

Pokines, J. 2011. Avian remains from Khonkho Wankane, an urban and ceremonial center in the southern Lake Titicaca Altiplano. International Journal of Osteoarchaeology. En Prensa.

Privitera, C. 2011. "Los camélidos de un contexto doméstico agro-alfarero en la precordillera mendocina (San Ignacio, Potrerillos). Una aproximación osteométrica". Tesis de Licenciatura. F.F.yL., U.N.Cuyo. Medoza, MS.

Reiner, R. y F. Bryant. 1986. Botanical Composition and Nutritional Quality of Alpaca Diets in Two Andean Rangeland Communities. Journal of Range Management 39:424-427.
Rocha, O. 2004. Crianza familiar de llamas. En: K. van't Hooft (ed), Gracias a los animales. Análisis de la crianza pecuaria familiar en Latinoamérica, con estudios de casos en los valles y el altiplano de Bolivia, pp.257-286, Plural, Bolivia.

Roig, F., E. Martínez Carretero y E. Méndez. 2000. Vegetación de la Provincia de Mendoza. En: Abraham, M. y F. Rodríguez Martínez (eds.), Argentina: recursos y problemas ambientales de la Zona Árida, TI, pp.63-66. Programa de Cooperación para la Investigación. Junta de Gobierno de Andalucía- Universidades y Centros de Investigación de la Región Andina Argentina.

Sanhueza, L. 2004. “Estilos Tecnológicos e Identidades Sociales durante el Periodo Alfarero Temprano en Chile Central: una mirada desde la alfarería". para grado de Magíster en Arqueología. Facultad de Ciencias Sociales, Universidad de Chile, pp.83, Santiago.

Sanhueza, L. y F. Falabella. 2008. Cuadernillo Taller: Introducción al análisis de cerámica en laboratorio. Departamento de Antropología, Facultad de Ciencias Sociales, Universidad de Chile. Santiago. MS.

Stark M. 1999. Social dimensions of technical choice in Kalinga ceramic traditions. En: E. Chilton (ed.), Material meanings. Critical approaches to the interpretation of material culture, cap.3, pp.24-43. The University of Utah Press. Salt Lake City.

Tixier, J.; M. Inizan y H. Roche. 1980. Prehistoire de la Pierre Taillée. I Terminologie et Technologie. Cercle de Echerches et d'Etudes Préhistoriques, Valbonne, France.

Torrence, R. 1995. Strategies for Moving on Lithic Studies. En: Philip Carr (ed.), The Organization of North American Prehistoric Chipped Stone Tool Technologies, International Monographs in Prehistory, 7:123-136, Archaeological Series

Tomka, S. 1992. Vicuñas and Llamas: Parallels in Behavioral Ecology and Implications for the Domestication of Andean Camelids. Human Ecology 20:407-433.

Valpreda, C. y A. Elissonde. 2002. Impacto del Dique Potrerillos en la dinámica territorial del noroeste de Mendoza. Revista Proyección N², U.N.Cuyo, Mendoza.

Wheeler, J. 1991. Origen, evolución y status actual. En: S. Fernández-Baca (ed.), Avances y perspectivas del conocimiento de los camélidos sudamericanos, Oficina Regional de la FAO para América Latina y el Caribe, pp.11-48, Santiago.

Wheeler, J. y J. Laker. 2009. The Vicuña in the Andean Altiplano. En: Ian Gordon (ed), The Vicuña: The Theory and Practice of Community Based Wildlife Management pp.21-33.

Yacobaccio, H. D., C. M. Madero y M. P. Malmierca. 1998. Etnoarqueología de Pastores Surandinos. Grupo Zooarqueología de Camélidos, Buenos Aires. 